- Crackdown on Illegal Wildlife Trade

- Acid Rain: States Prod EPA (Will A. Irwin)

18

53

US / Canada

- The Uniform Transboundary Reciprocal Access Act (Armin Rosencranz)

\section{SELECTED DOCUMENTS}

ECE

- Declaration on Air Pollution by Motor Vehicles

Council of Europe

- Air Pollution

OECD

Environment: Resource for the Future (Declaration)
IPU

- Implementation of the Conclusions and Recommendations of the Conference on Environment

Conclusions by Environment Ministers of Summit Countries 35 EC

- Pollution by Hydrocarbons

ASEAN

- Agreement of the Conservation of Nature and Natural Resources

OECD/IEA

-Recommendation on Energy and the Environment $\quad 70$ African Environment Conference: Suggested Action $\quad 71$ LOS / Prep.Com.

- Declaration

Migratory Species Conv

\title{
AUTHOR INDEX OF VOLUME 15
}

Amir, Shaul, 56

de Klemm, Cyrille, 81

Dirnberger, Franz, 14

Irwin, Will A., 53

Kessel, Hans, 20

Okidi, C.O., 43
Pedroli, R., 100

Rosencranz, Armin, 105

Soell, Hermann, 14

Vygen, Hendrick, 6

Waite, A.J., 115

Zimmermann, Klaus, 20 